\title{
A controlled investigation of continuing pain education for long-term care staff
}

\author{
Omeed O Ghandehari $\mathrm{MA}^{1,2}$, Thomas Hadjistavropoulos $\mathrm{PhD}^{1,2}$, Jaime Williams $\mathrm{PhD}^{2}$, Lilian Thorpe MD PhD ${ }^{3}$, \\ Dennis P Alfano $\mathrm{PhD}^{1}$, Vanina Dal Bello-Haas $\mathrm{PhD}^{4}$, David C Malloy $\mathrm{PhD}^{5}$, Ronald R Martin $\mathrm{PhD}^{6}$, \\ Omar Rahaman $\mathrm{MD}^{7}$, Sandra MG Zwakhalen $\mathrm{PhD}^{8}$, R Nicholas Carleton PhD ${ }^{1}$, Paulette V Hunter PhD ${ }^{9}$, Lisa M Lix PhD ${ }^{10}$
}

\begin{abstract}
OO Ghandehari, T Hadjistavropoulos, J Williams, et al. A controlled investigation of continuing pain education for long-term care staff. Pain Res Manag 2013;18(1):11-18.
\end{abstract}

BACKGROUND: The underassessment and undertreatment of pain in residents of long-term care (LTC) facilities has been well documented. Gaps in staff knowledge and inaccurate beliefs have been identified as contributors.

OBJECTIVES: To investigate the effectiveness of an expert-based continuing education program in pain assessment/management for LTC staff. METHODS: Participants included 131 LTC staff members who were randomly assigned to either an interactive pain education (PE) program, which addressed gaps in knowledge such as medication management, or an interactive control program consisting of general dementia education without a specific clinical focus. Participants attended three sessions, each lasting $3 \mathrm{~h}$, and completed measures of pain-related knowledge and attitudes/beliefs before, immediately after and two weeks following the program. Focus groups were conducted with a subset of participants to gauge perception of the training program and barriers to implementing pain-related strategies.

RESULTS: Analysis using ANOVA revealed that PE participants demonstrated larger gains compared with control participants with regard to pain knowledge and pain beliefs. Barriers to implementing pain-related strategies certainly exist. Nonetheless, qualitative analyses demonstrated that PE participants reported that they overcame many of these barriers and used pain management strategies four times more frequently than control participants. CONCLUSIONS: Contrary to previous research, the present study found that the interactive PE program was effective in changing pain beliefs and improving knowledge. Continuing PE in LTC has the potential to address knowledge gaps among front-line LTC providers.

Key Words: Dementia; Education; Long-term care; Nursing home

\section{Une exploration contrôlée de la formation continue sur la douleur auprès du personnel de soins de longue durée}

HISTORIQUE : La sous-évaluation et le traitement insuffisant de la
douleur des résidents en soins de longue durée (SLD) sont bien documen-
tés. Les lacunes du savoir et les convictions erronées du personnel font
partie des éléments qui y contribuent. OBJECTIFS : Explorer l'efficacité d'un programme de formation continue sur l'évaluation et la prise en charge de la douleur, fondé sur des experts et destiné au personnel en SLD.

MÉTHODOLOGIE : Cent trente et un membres du personnel en SLD répartis au hasard entre un programme interactif de formation sur la douleur (FD) (qui corrigeait les lacunes du savoir, telles que la prise en charge des médicaments) ou un programme témoin interactif de formation générale sur la démence, sans sujet clinique précis, ont participé. Les participants ont assisté à trois séances de trois heures chacune et ont répondu à des mesures sur les connaissances, les attitudes et les convictions liées à la douleur avant, immédiatement après et deux semaines après le programme. Des groupes de travail, formés d'un sous-groupe de participants, ont permis d'évaluer la perception du programme de formation et les obstacles à la mise en œuvre de stratégies liées à la douleur.

RÉSULTATS : Au moyen d'analyses de variance, les participants à la FD ont démontré des acquis à l'égard des connaissances et des convictions sur la douleur par rapport aux participants témoins. De toute évidence, il existe des obstacles à la mise en œuvre de stratégies liées à la douleur. Néanmoins, selon les analyses qualitatives, les participants à la FD déclaraient avoir repoussé bon nombre de ces obstacles et avoir utilisé les stratégies de prise en charge de la douleur quatre fois plus que les participants témoins.

CONCLUSIONS : Contrairement aux recherches antérieures, la présente étude a établi que le programme interactif de FD était efficace pour modifier les convictions et améliorer les connaissances vis-à-vis de la douleur. Une FD continue en SLD a le potentiel de corriger les lacunes du savoir chez les dispensateurs de SLD en première ligne.

resulting in inadequate clinical practices $(2,4,13,16)$. Zwakhalen et al (14) found that LTC staff had deficits in knowledge concerning several aspects of pain care. For example, LTC staff failed to recognize the value of fixed regular analgesia, and were divided with respect to beliefs about the addictive potential of medications and the rates of pain in older adults compared with younger individuals.

Self-report is the most common strategy used in pain assessment (13). However, this method poses obvious challenges for older adults with severe dementia due to communication difficulties. Effective behavioural measures for pain assessment in this population exist $(17,18)$ but front-line staff are often not aware of them and/or have not received training in their use (13). undertrained in pain assessment and management and, as a result, may have gaps in their knowledge base and/or hold inaccurate beliefs $(12,15)$

${ }^{1}$ Department of Psychology; ${ }^{2}$ Centre on Aging and Health, University of Regina, Regina; ${ }^{3}$ Department of Community Health and Epidemiology and Department of Psychiatry, University of Saskatchewan, Saskatoon, Saskatchewan; ${ }^{4}$ School of Rehabilitation Science, McMaster University, Hamilton, Ontario; ${ }^{5}$ Faculty of Kinesiology and Health Studies; ${ }^{6}$ Faculty of Education, University of Regina, Regina, Saskatchewan; ${ }^{7}$ Meadowlark Health Centre, Edmonton, Alberta; ${ }^{8}$ Department of Health Services Research, Maastricht University, Maastricht, The Netherlands; ${ }^{9}$ St Thomas More College; ${ }^{10}$ School of Public Health, University of Saskatchewan, Saskatoon, Saskatchewan

Correspondence: Dr Thomas Hadjistavropoulos, Department of Psychology, University of Regina, Regina, Saskatchewan S4S 0 A2.

Telephone 306-585-4457, fax 306-337-2321, e-mail thomas.hadjistavropoulos@uregina.ca 


\section{Pain management education}

Jones et al (12) discussed the potential benefits of staff education with respect to pain-related knowledge acquisition and changing beliefs and attitudes, as well as understanding the role of perceived patient and institutional barriers to appropriate pain detection and treatment (19). Their educational program was provided to staff in 12 LTC facilities, with six facilities serving as control sites $(12,20)$. The educational groups did not differ from the control groups following the educational program with regard to knowledge acquisition or beliefs. However, the study and practical aspects of the educational approach had limitations. A significant methodological limitation was related to the high turnover rate among the staff, resulting in a different group of staff members responding to survey questionnaires pre- and postintervention. As the researchers stated, "staff all received different exposure to the intervention, diminishing its potency" (12). Moreover, the outcome measure had limitations because the correct response to several of the items appeared to be unclear. Finally, the approach to education was not primarily interactive; rather, it included shared take-home materials and videos, with only four $30 \mathrm{~min}$ face-to-face seminars, five weeks apart.

Another relevant study was described by Long et al (21) and Long (22). These authors outlined a pilot study of a multicomponent pain assessment and management program. Didactic education was one component of this program, which had the overall goal of a "total overhaul of policies, procedures, and documentation of pain assessment and management" (22). Although Long (22) did not use a control group and only had a very small sample of 10 nursing assistants and 14 professional staff (nursing, social work, dietary), the results were encouraging. Long et al (21) reported patient outcomes, noting significant reductions in chronic and acute pain that were maintained during a one-year period. Long et al (21) also reported that staff members' knowledge about pain improved, attitudes changed in the expected direction and barriers were mitigated following the educational component of the program compared with baseline.

\section{Constructivist approach to continuing education}

Educational meetings or workshops are a common method for delivering continuing education (23), providing an opportunity for instruction, interaction and reflection. Varying approaches to teaching/ learning have been implemented based on theories about the process of learning and the outcomes of interest. A common approach to interprofessional learning involves didactic instruction in which the instructor lectures and the interaction with the participants is limited (23). This approach is based on the notion that the participants' intrinsic motivation for learning, or the potential for external rewards resulting from learning, will be sufficient for optimal learning outcomes. The purely didactic format can be contrasted with the constructivist approach to interprofessional education (24), which can incorporate both didactic (eg, lecture) and interactive (eg, roundtable discussion) techniques. Constructivist approaches consider the construction of knowledge and emphasize a relational model involving interaction and shared articulation of information between teacher and learner and among peer learners. In other words, constructivism emphasizes experiential knowledge consistent with the learner's world view, and encourages learners to understand how their attitudes and values mediate knowledge (25). Compared with a traditional didactic approach, constructivist approaches concentrate on the setting of collaborative learning objectives with questioning always encouraged, allowing the teacher/facilitator to move away from the curriculum when necessary to accommodate the individual needs of the student group (26). In a review of 81 trials of continuing education meetings, Forsetlund et al (23) found that approaches consistent with the constructivist perspective were more effective than purely didactic approaches.

The purpose of the present study was to examine a novel, expertbased continuing pain assessment/management pain education (PE) program tailored specifically for LTC staff within the context of a controlled investigation. We aimed to use methods that overcome the challenges reported by Jones et al (12) and improve on the design described by Long et al (21) through the use of a control group and a larger sample size. As mentioned above, we sought to use an effective, established method of instruction, delivering both PE and control sessions in accordance with constructivist models (mixed interactive and didactic approach). The purpose of our design was not to evaluate the effect of interactivity on imparting pain knowledge. In contrast, we incorporated the control group (participating in seminars focusing on dementia-related knowledge without a focus on practical or symptom management issues) to control for expert attention, interaction with experts/peers and participation in continuing education. Our PE program was aimed at improving staff beliefs, attitudes and overall knowledge with respect to pain management. Our hypothesis was that, compared with the control group, PE participants would demonstrate increased knowledge related to pain as well as shifts in pain beliefs (ie, toward beliefs that pain can be managed both by pharmacological and nonpharmacological interventions).

\section{Participants}

\section{METHODS}

The participants comprised 131 LTC staff recruited from two large health regions. The sample included nurses $(n=70)$ and special care aides (SCAs; $\mathrm{n}=61$ ). SCAs are unregulated health care professionals whose role is to assist clients in their tasks of daily living, although specific job descriptions vary among settings (27). While SCAs do not administer medications, they assist with pain intervention strategies. With respect to pain management, given that they have very frequent contact with LTC residents, SCAs are often the first to notice signs of pain and report these to nursing staff who administer medications or take other appropriate actions. Moreover, SCAs assist with nonpharmacological interventions (eg, repositioning, rest, ice).

Informed consent was obtained from all participants. Administrators from each LTC facility were asked to inform nursing and SCA staff of the investigation involving continuing education opportunities. The administrators were asked to stress the voluntary nature of participation and to explain that participants would be asked to complete confidential knowledge and other questionnaires before and after the sessions. They also informed staff members that they could participate during regular work hours (ie, they would receive their regular salary while attending the sessions). Participants who signed up for participation were assigned to one of 12 groups within the broader PE condition or a control condition (ie, six groups per condition).

On arrival for the first session, research personnel met with the participants, who were informed that the purpose of the study was to compare two different education programs on knowledge, practices and attitudes, and were then asked to read and sign consent forms. Participants were randomly assigned to either a control session or a PE session. They were also informed that the specific content of the sessions would vary as a function of group assignment.

\section{PE program and control condition}

At the time of manuscript preparation, there were no routine continuing PE programs offered for LTC staff within the health regions where the study was conducted (ie, no set standard for continuing PE). The PE program used in the present study was developed based on the results of a larger project $(28,29)$ in which staff input was collected through focus group sessions on issues related to pain management and quality of life in LTC. Kaasalainen et al (28) provide a description of the focus groups, during which staff provided input into perceived knowledge gaps about pain management. More specifically, the transcripts from the focus group sessions were re-examined for the purposes of the present study, with a focus on identifying statements related to barriers to effective pain care in LTC. Once a list of barriers and knowledge gaps was created based on the focus group sessions, the PE sessions were developed by addressing the themes and gaps. The knowledge gaps/barriers that were identified by LTC staff focus group participants related to the areas of 
medication management, pain assessment, management of behavioural disturbance resulting from pain, nutritional issues (of relevance to pain and pain management), physical function and individual-centred care.

These areas were then incorporated into a three-session PE format, with each session focused on a different theme. Session 1 focused on meeting the challenges of pain, including the most effective approaches to assessing and managing pain in LTC based on empirical evidence. The session covered both pharmacological and nonpharmacological approaches. Session 2 involved discussion of nutrition in relation to pain/pain management. It also covered physical functioning/physical activity (with an emphasis on pain and prevention of falls). Finally, session 3 focused on issues related to individual-centred care in the assessment and management of pain. In this session, strategies were also presented for managing the patient's behavioural disturbances and identifying the potential influence of pain on problematic behaviour.

The control sessions were designed to control for expert attention, interaction with experts and participation in continuing education. They differed from the PE sessions in terms of specific content covered, and focused on broad and common themes that were not expected to be readily translatable to clinical practices by front-line staff. The session-to-session breakdown of the control condition was as follows: session 1 covered a description and understanding of the neuropsychological approaches used in the assessment of patients with cognitive impairments; session 2 covered the symptoms and causes of delirium and various forms of dementia; session 3 covered psychiatric disorders encountered in LTC including their symptoms and causes (eg, contribution of genetic vulnerabilities). Although some participants may have found the material relevant to their practice, the control sessions were not designed specifically to offer any advice, suggestions, or recommendations that had direct implications for day-today clinical care. Nevertheless, similar to the PE groups, the facilitators of the control groups presented the material in an interactive format, encouraging discussion, participation and critical thinking. For example, participants were invited to engage in roundtable discussions (eg, "What do you think of when you hear the term 'neuropsychology'?") and brainstorming (eg, "How could a symptom of behavioural disturbance be related to brain functioning?").

Experts acted as instructors/facilitators and developers of the PE sessions and the control sessions by following a structured presenter guide designed to ensure a consistent interactive format across all training sessions and study conditions. Interactivity was key to the sessions and facilitators used case-based materials, stimulated dialogue, encouraged questions and supported critical thinking. All sessions (PE and control) occurred once per week for three weeks and each was $3 \mathrm{~h}$ in duration (ie, each participant received $9 \mathrm{~h}$ of instruction) with a brief break halfway through each session. Participants were provided with take-home materials for future reference. Where applicable, LTC facilities were offered staff replacement costs (to be able to release their staff to attend the training sessions). Nurses and SCAs attended the sessions together. The participants for each group came from a number of facilities but met in centralized locations. Overall, attendance for both PE and control sessions was excellent: a total of three participants from the PE condition (4.5\%) did not complete sessions 2 and 3; two control group participants (3.1\%) did not complete session 2; and four control participants (6.2\%) did not complete session 3. All participants who attended at least one control or PE session were included in the analyses.

\footnotetext{
Measures

Demographic questionnaire: Demographic information was collected using a brief questionnaire that included questions regarding age, job status, education, years of experience in health care and years of experience in LTC.

Pain Knowledge and Beliefs Questionnaire (PKBQ) (14): The PKBQ contains 17 pain-related statements derived from the literature to identify gaps in knowledge and inaccurate beliefs regarding pain and dementia among nursing staff. Lower scores indicate more knowledge.
}

The questionnaire has been found to be valid and internally consistent (Cronbach's alpha $=0.78)(14)$. The baseline, posteducation and follow-up Cronbach's alphas for the current study data were $0.65,0.72$ and 0.74 , respectively. The average interitem correlations for the three phases of the study were $0.11,0.15$ and 0.16 , respectively. Modified Pain Beliefs Questionnaire (PBQ) $(30,31)$ : The modified PBQ is a 20 -item questionnaire divided into three subscales: organic beliefs, psychological beliefs and aging beliefs. Scoring higher on the aging beliefs subscale reflects maladaptive beliefs about pain in old age. The other two subscales tend to be inversely related, in that individuals who are more inclined to focus on organic factors minimize the importance of psychological factors and vice versa. Importantly, recent work has demonstrated that PBQ scores can be altered as a result of psychological intervention (32).

The PBQ has demonstrated criterion validity $(30,33)$. Higher scores on the psychological beliefs subscale have been associated with better treatment outcomes and greater perceived control over pain $(30,34,35)$. Higher scores on the organic beliefs subscale relate to the belief that medical professionals and other influential individuals have more control over the pain experience than the patient and have been associated with poorer outcomes and greater disability (33). In addition, Edwards et al (30) demonstrated significant concurrent validity for the PBQ organic beliefs subscale and for the PBQ psychological beliefs subscale. Finally, the PBQ has satisfactory reliability $(30,31)$. For the present study sample, at baseline, posteducation and follow-up, Cronbach's alphas were as follows: organic beliefs subscale alphas were $0.69,0.66$ and 0.75 ; psychological beliefs subscale alphas were 0.73 , 0.77 and 0.76 ; and aging beliefs subscale alphas were $0.80,0.79$ and 0.82 , respectively. Mean interitem correlations for the three study phases were: organic beliefs subscale $0.21,0.18$ and 0.26 ; psychological beliefs subscale $0.40,0.46$ and 0.44 ; and aging beliefs subscale 0.35 , 0.33 and 0.38 , respectively.

Session content knowledge test (SCKT): Acquisition of pain-related knowledge was evaluated using the 28-item SCKT. This test was developed by session presenters, who each submitted two to three session-relevant content-based multiple choice questions. Baseline, posteducation, and follow-up SCKT scores (based on the sum of the correct answers to the pain-related questions) were used.

\section{Procedure}

Each of the 131 participants completed a baseline set of questionnaires two weeks before the beginning of the educational sessions. The set included the brief demographic questionnaire, the PKBQ (14), the modified PBQ $(30,31)$ and the SCKT. The same questionnaires (with the exception of the demographics questionnaire) were administered immediately after the completion of the three educational sessions and again at follow-up two weeks after the completion of the sessions.

\section{Quantitative analysis}

To determine whether participants in the PE groups and control groups differed from one another, several univariate analyses of the groups were conducted using $\chi^{2}$ tests and ANOVA. Subsequently, preliminary mixed-model ANOVAs were used, involving the following factors: 2 (condition: PE versus control) $\times 3$ (time: baseline, post-training and follow-up) $\times 6$ (group: one of six learning groups within PE or control condition). The rationale for initially including group (ie, six groups per condition) as a fixed factor related to the groups being nested within condition (ie, PE or control) and testing time, which also meant that participants within each group were not independent from one another. Because the number of groups was insufficient to accurately estimate the variance of the group effect, it was included as a fixed factor (36). This made it possible to determine whether there were detectable differences in the results across groups. Nevertheless, given that the initial preliminary analysis demonstrated that the group factor was not significantly implicated in any main effect or interaction, it was removed from the final analyses. Therefore, the reported analyses used to test the hypotheses were 


\begin{tabular}{|c|c|c|c|}
\hline & Baseline & Posteducation & Follow-up \\
\hline \multicolumn{4}{|c|}{ Pain education condition } \\
\hline $\mathrm{PKBQ}^{*}$ & $42.64 \pm 5.85$ & $37.68 \pm 6.79$ & $37.81 \pm 6.45$ \\
\hline PBQorg $^{\dagger}$ & $29.18 \pm 4.12$ & $28.64 \pm 4.22$ & $29.13 \pm 4.80$ \\
\hline PBQpsy $^{\dagger}$ & $17.27 \pm 3.65$ & $18.46 \pm 3.35$ & $18.12 \pm 3.32$ \\
\hline $\mathrm{PBQage}^{\dagger}$ & $23.96 \pm 5.39$ & $20.53 \pm 4.43$ & $21.14 \pm 5.01$ \\
\hline $\mathrm{SCKT}^{\dagger}$ & $11.57 \pm 2.34$ & $13.90 \pm 2.73$ & $13.60 \pm 2.61$ \\
\hline \multicolumn{4}{|c|}{ Control condition } \\
\hline PKBQ* & $43.22 \pm 7.43$ & $43.14 \pm 7.01$ & $43.19 \pm 6.79$ \\
\hline PBQorg $^{\dagger}$ & $29.15 \pm 4.78$ & $28.08 \pm 3.78$ & $28.27 \pm 3.73$ \\
\hline PBQpsy $^{\dagger}$ & $17.08 \pm 3.24$ & $17.04 \pm 3.27$ & $16.32 \pm 2.93$ \\
\hline PBQage $^{\dagger}$ & $24.13 \pm 5.22$ & $23.66 \pm 5.12$ & $23.46 \pm 5.19$ \\
\hline $\mathrm{SCKT}^{\ddagger}$ & $10.95 \pm 2.25$ & $11.52 \pm 2.34$ & $11.75 \pm 2.50$ \\
\hline
\end{tabular}

Data presented as mean $\pm S D$. *Lower scores reflect more accurate beliefs about pain management in long-term care; ${ }^{\dagger}$ Lower scores reflect lower endorsement of subscale factors in the pain experience; ${ }^{\ddagger}$ Lower scores reflect lower knowledge content. PBQage Pain Beliefs Questionnaire Aging subscale; PBQorg Pain Beliefs Questionnaire Organic Beliefs subscale; PBQpsy Pain Beliefs Questionnaire Psychological Beliefs subscale; $P K B Q$ Pain Knowledge and Beliefs Questionnaire; SCKT Session Content Knowledge Test

2 (condition: PE versus control) $\times 3$ (time: testing times) mixedmodel ANOVAs.

All main effects and interactions were tested on the mixed model. These mixed-model ANOVAs accounted for correlation among repeated measurements on subjects; tests of the repeated measures interaction effects were used to assess whether the change over time was constant across the education/control conditions. For all models in which the assumption of sphericity was violated, Greenhouse-Geisser correction values were used (37). It is recommended that, when a significant interaction is present, it should be interpreted foremost because main effects are dependent on the levels of the other factor (38). Therefore, for ease of interpretation, main effect results are not presented for instances in which significant interactions exist (ie, interpretation of main effects would not be meaningful in such instances). Follow-up comparisons of statistically significant interactions were conducted using Tukey's honestly significant difference (HSD) tests.

\section{Focus group sessions}

A random subset of 28 PE (16 nurses, 12 SCAs) and 29 control (13 nurses, 16 SCAs) participants were invited to separate focus group discussions (divided among job title and study condition into four separate groups and conducted at the time of follow-up, two weeks postintervention). These discussions pertained to participants' involvement within the educational sessions to gain feedback about session content and format. Participants also discussed barriers and facilitators for implementing better pain management strategies. The focus group discussions were audio-recorded and transcribed for further analysis.

Analysis of focus group transcripts was facilitated using the software QSR NVivo version 8 (QSR International, USA). Thematic analysis (39) comprised the framework for examining the data. Two members of the research team analyzed the data, collaboratively reaching consensus on the coding framework and discrepancies throughout. Data were first coded into broad categories related to session content (ie, the topics covered in the sessions) and format (ie, how the sessions were delivered and logistic issues). Positive and negative impressions were coded separately for control versus PE conditions to make comparisons. A third category emerged from examination of the data, which related to LTC staff perceptions of barriers/facilitators to implementing pain management strategies in their practice. Again, this text was examined separately for control versus $\mathrm{PE}$ conditions.

\section{RESULTS}

Overall, participants had a mean $( \pm$ SD) age of $44.1 \pm 12.5$ years, $17.6 \pm 11.8$ years of experience working in health care and $12.0 \pm 9.5$ years of experience working in LTC. A $\chi^{2}$ test of independence demonstrated that the frequency of participants was not significantly different with respect to job status across the 12 groups $\left(\chi^{2}[4, \mathrm{n}=131]=55.02\right.$; $\mathrm{P}=0.12)$. A one-way ANOVA revealed no significant differences between groups for age $(F[11,118]=0.87 ; \mathrm{P}=0.58)$, years of work experience in $\operatorname{LTC}(\mathrm{F}[11,119]=0.95 ; \mathrm{P}=0.50)$ and years of experience in the health care field $(F[11,119]=1.00 ; \mathrm{P}=0.45)$. Moreover, participants in the experimental condition did not differ from participants in the control condition with respect to job status $\left(\chi^{2}[4, n=131]=8.56\right.$; $\mathrm{P}=0.07)$, age $(\mathrm{t}[128]=0.55 ; \mathrm{P}=058)$, years of work experience in LTC $(t[129]=1.71 ; P=0.09)$ or years of experience in the health care field $(\mathrm{t}[129]=0.78 ; \mathrm{P}=0.44)$.

\section{Knowledge and views about pain}

Knowledge and views about pain were assessed using a 2 (condition) $\times 3$ (time) mixed-model ANOVA with the PKBQ (14) as the dependent variable (see Table 1 for descriptive statistics for all measures and Figure 1 for a graphic illustration of the results). Given that lower PKBQ scores reflected increased knowledge, consistent with expectations, a significant time by condition interaction was found $\left(\mathrm{F}[2,206]=14.22, \eta^{2}=0.11 ; \mathrm{P}<0.001\right)$, with Tukey's HSD comparisons indicating that $\mathrm{PE}$ participants scored lower (reflecting better knowledge) than the control participants at posteducation $(\mathrm{HSD}=2.77 ; \mathrm{q}[0.05,206,2]=14.57)$ and follow-up $(\mathrm{HSD}=2.77$; $\mathrm{q}[0.05,206,2]=14.77)$. Moreover, PE participant scores significantly decreased from baseline to posteducation (reflecting improved pain knowledge; $\mathrm{HSD}=2.77 ; \mathrm{q}[0.05,206,2]=9.81$ ) and from baseline to follow-up ( $\mathrm{HSD}=2.77$; q $[0.05,206,2]=9.55)$, but not from posteducation to follow-up. No other follow-up comparisons were significant.

\section{Pain beliefs}

Organic beliefs about pain: Organic beliefs about pain were assessed using the organic beliefs subscale of the PBQ (30) (Table 1). A $2 \times 3$ mixed-model ANOVA indicated no significant main or interaction effects. These results are summarized in Figure 1.

Psychological beliefs about pain: Psychological beliefs were assessed using the corresponding subscale of the PBQ (30) (Table 1). Consistent with expectations, the time by condition interaction in the $2 \times 3$ mixed-model ANOVA was significant $(F[1.77,188.83]=5.16$, $\eta^{2}=0.04 ; \mathrm{P}=0.009$ ). Tukey's HSD comparisons indicated that PE participants scored higher than the control participants at posteducation $(\mathrm{HSD}=2.77 ; \mathrm{q}[0.05,188.83,1.77]=7.25)$ and follow-up $(\mathrm{HSD}=2.77 ; \mathrm{q}[0.05,188.83,1.77]=9.18)$. PE participant scores significantly increased from baseline to posteducation $(\mathrm{HSD}=2.77$; $\mathrm{q}[0.05,188.83,1.77]=4.34)$ and from baseline to follow-up $(\mathrm{HSD}=2.77$; $\mathrm{q}[0.05,188.83,1.77]=3.09)$, but not from posteducation to follow-up. No other follow-up comparisons were significant. These results are summarized in Figure 1.

Beliefs about pain in aging: Beliefs about pain and aging were assessed using the corresponding subscale of the PBQ (31) (Table 1). Consistent with expectations, in the $2 \times 3$ mixed-model ANOVA, a significant time by condition interaction was found $(\mathrm{F}[1.85,194.71]=7.12$, $\left.\eta^{2}=0.06 ; \mathrm{P}=0.001\right)$ wherein Tukey's HSD planned comparisons demonstrated that $\mathrm{PE}$ participants scored lower than the control participants at posteducation $(\mathrm{HSD}=2.77 ; \mathrm{q}[0.05,194.71,1.85]=10.49)$ and at follow-up $(\mathrm{HSD}=2.77 ; \mathrm{q}[0.05,194.71,1.85]=7.77)$. As expected, PE participant scores decreased significantly from baseline to posteducation $(\mathrm{HSD}=2.77 ; \mathrm{q}[0.05,194.71,1.85]=8.25)$ and from baseline to follow-up ( $\mathrm{HSD}=2.77$; $\mathrm{q}[0.05,194.71,1.85]=6.77)$, but not from posteducation to follow-up. No other follow-up comparisons were significant. These results are summarized in Figure 1.

\section{Session content knowledge}

Session content was assessed using the SCKT (Table 1). Consistent with the study hypotheses, $2 \times 3$ mixed-model ANOVA results 


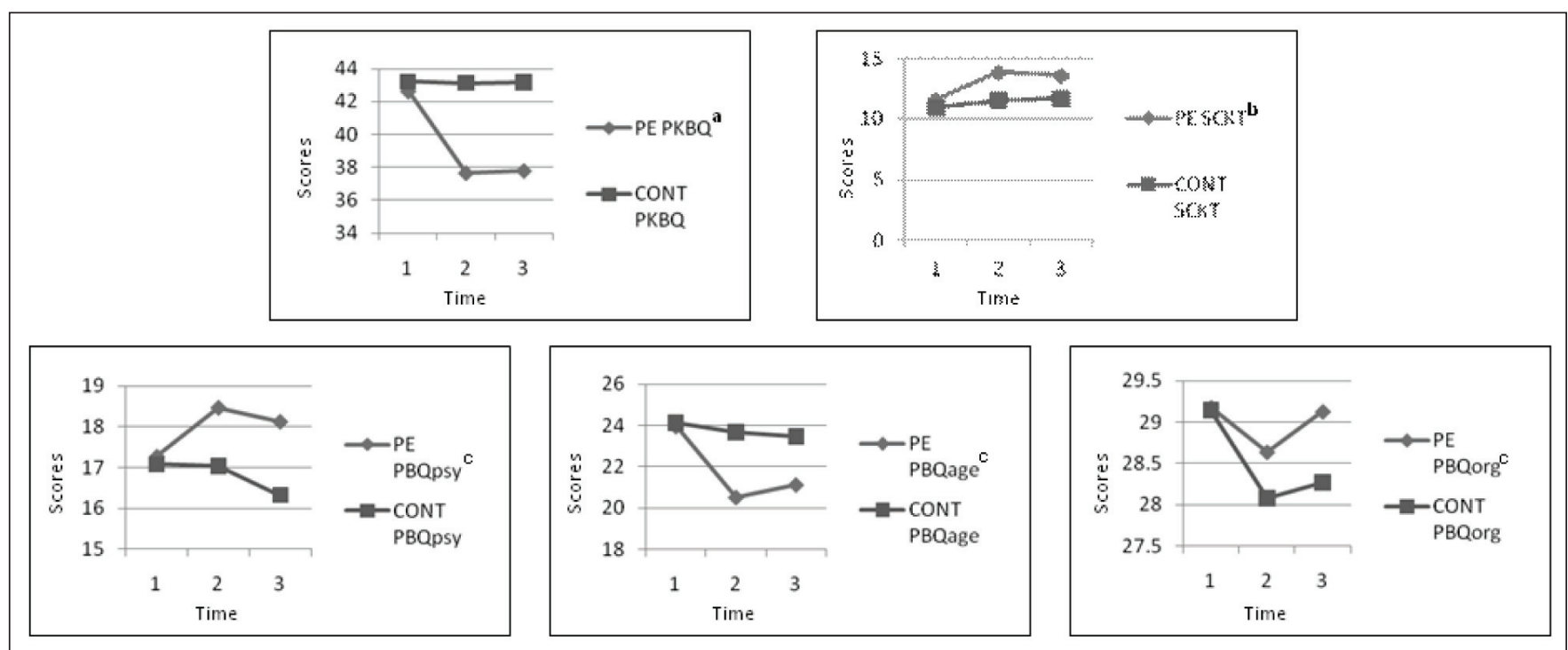

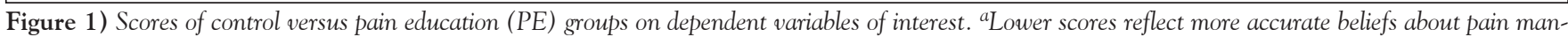
agement in long-term care; ${ }^{b}$ Lower scores reflect lower knowledge content; ${ }^{C}$ Lower scores reflect lower endorsement of subscale factors in the pain experience. CONT Control; PBQage Pain Beliefs Questionnaire Aging subscale; PBQorg Pain Beliefs Questionnaire Organic Beliefs subscale; PBQpsy Pain Beliefs Questionnaire Psychological Beliefs subscale; PKBQ Pain Knowledge and Beliefs Questionnaire; SCKT Session Content Knowledge Test

indicated a significant time by condition interaction $(F[2,224]=9.48$, $\eta^{2}=0.06 ; \mathrm{P}<0.001$ ). Planned comparisons using Tukey's HSD demonstrated that $\mathrm{PE}$ participants scored higher than the control participants at posteducation $(\mathrm{HSD}=2.77 ; \mathrm{q}[0.05,224,2]=16.26)$ and at follow-up $(\mathrm{HSD}=2.77 ; \mathrm{q}[0.05,224,2]=12.67)$. PE participant scores increased significantly from baseline to posteducation $(\mathrm{HSD}=2.77$; $\mathrm{q}[0.05,224,2]=11.35)$ and from baseline to follow-up (HSD $=2.77$; $\mathrm{q}[0.05,224,2]=9.92)$, but not from posteducation to follow-up. Interestingly, control participant scores did not change from baseline to posteducation, but did increase slightly from baseline to follow-up $(\mathrm{HSD}=2.77 ; \mathrm{q}[0.05,224,2]=3.09)$. Nevertheless, their scores did not change significantly from posteducation to follow-up.

\section{Focus group sessions}

General overview of qualitative results: Participants in both the PE and control conditions were highly supportive of and enthusiastic about the interactive nature of instruction and the quality and variety of expert presenters, but believed that a lot of information was presented. Given that each of these elements was held constant across conditions, the homogeneity of responses in these areas is encouraging. While PE and control participants expressed satisfaction with the content of the groups, control participants indicated that they would have appreciated more specific strategies for applying the session information to their patients. This is not surprising given that concrete tools were only provided to PE participants, and this may be construed as a confound in the study (ie, that the group content may not have been perceived equally favourably by the participants in the two conditions). Nevertheless, participants in both conditions did attempt to apply the information to their clinical care. The PE participants were more successful, likely due to their exposure to tools and strategies.

Format of sessions: Participant comments supported the use of interactive instruction methods and expert-facilitated presentations. Both groups made positive remarks about the interactive nature of the sessions and preferred this method to other training sessions they attended in the past. A nurse in the control condition summarized the importance of interactivity as follows:

I find when it's more interactive I get a lot more out of it than when there's a lot of slides and a lot of home reading. I'm not very good at it 'cause once I leave here I'm kind of in family mode so I do, I retain a lot more when it's interactive. And I really enjoyed the small groups, which I took back to my place of employment and I said this is probably one of the best conferences/workshop seminars I have attended, where the groups are smaller and you feel freer to talk.

Both groups agreed that the quality and variety of expert session presenters was a major strength. This feedback is best captured by the following comment from a nurse in the PE condition:

The presenters were amazing. Everybody was very captivating. It was great. It was just a different way of looking at things and opened my eyes more I guess.

Both groups described difficulty with the amount of information presented during the sessions, although this appeared to be more pronounced among the control participants. Participants noted that the material was often presented too quickly to be adequately absorbed in the sessions, but that the addition of take home materials counterbalanced this to an extent. The overwhelming nature of the information is indicated by statements such as the following by a nurse in the control condition: "...like everyone else is saying, I was overwhelmed. It was too much in a small period of time." Another concern about session format was expressed by the PE participants (primarily); they felt positively about the SCA and nurses attending the sessions together, but they would have liked for other LTC staff (eg, physicians) to be in attendance to better engender an interdisciplinary, teambased approach to pain management.

Session content: Overall, PE participants were far more satisfied and made more positive remarks about the content of the sessions compared with the control participants. PE participants regarded the practicality and relevancy of the PE session content material as interesting and captivating, which was reflected in comments such as "I thought it was a good mix of medical and nonmedical" (nurse, PE condition), and more specifically "Well I think that the PACSLAC [Pain Assessment Checklist for Seniors with Limited Ability to Communicate (40)] ...was excellent [and] that we should be using [it] and I'm hoping that somehow we can at least try it" (SCA, PE condition). PE participants indicated that the balance between pharmacological and nonpharmacological content of the PE sessions was appropriate. They did, however, suggest that more focused content coverage in other specific topic areas, such as dementia and the effect of dementia on pain, may have been beneficial.

Examination of control participants' comments highlighted concerns about the applicability and practicality of the materials presented 
in their sessions to LTC. Overall, they would have preferred receiving specific tools to aid them in their daily practice and were disappointed that these were not provided. This was not surprising because a key difference between the PE group and control condition was that the former included a clinical focus, tools for improving care and specificity to LTC. The overall lack of intervention-specific content is summarized by the following quotation by one nurse in the control condition:

I thought it was going to be more how to deal with residents, like how we could better ourselves for caring for the difficult residents too. Not just more of knowing what is going on. Not learning, we learned a lot of the theory behind a lot of the stuff but not necessarily what we could do to help these residents better.

Barriers and facilitators to knowledge application: Participants described positive and negative experiences while applying the knowledge that they gained through the sessions. Control and PE participants both identified similar challenges with respect to using new strategies for patient care (pain-related or otherwise). These barriers tended to relate to either difficult patient characteristics (eg, patient with dementia having difficulty communicating clearly their needs) or to systemic issues such as inadequate time, human resources and communication breakdown across professions. The impact and importance of attending to these barriers is underscored by the frustrations of one SCA who participated in the PE sessions:

I feel there was more barriers in following through with what we learned at the workshops... There are more barriers than there were ways to address those challenges... Like the barriers are nurses that are too busy or too in their way to listen to an SCA and what we have to say about it. The barriers are between the nurses and the doctors. Nurses can't all of a sudden push pain medication. Like someone's in pain they can't just give a Tylenol [acetaminophen] unless there's a standing order to give Tylenol, but lots of residents it's dependent on the doctor's order... It doesn't make any sense in long-term care. When our residents need pain medication they need it quickly. So I don't like to see someone in pain for even five minutes let alone a week. And I see it all the time.

Nevertheless, PE participants reported that they were able to implement tools learned through these sessions in their daily practice and reported more feelings of confidence with regard to dealing with these barriers as a result of attending the sessions than their control counterparts. To illustrate, PE participants made 137 references to ways they are able to overcome barriers and use skills compared with only 32 references made by control participants. The PE participants noted changes in their behaviour related to increased vigilance and awareness of the signs of pain, using nonpharmacological strategies, such as repositioning, in addition to medication, and increased and earlier use of medication including shifting to a regular schedule rather than on an 'as needed' basis. The same participants also expressed an increased sense of agency and confidence, as exemplified by the following statement made by an SCA participant in the PE condition: "I think for me we've been empowered to act on what we've learned".

\section{DISCUSSION}

The goal of the present study was to assess whether an interactive, expert-based PE program that highlights the dynamic relationship among factors influencing pain could increase knowledge and enhance attitudes about pain management relative to a control group receiving nonclinical general dementia education. In contrast to previous research that had significant methodological and practical limitations (12), and consistent with uncontrolled work involving a small sample $(21,22)$, our findings demonstrate that such a program can lead to meaningful and sustained improvements in pain related knowledge retained by LTC staff compared with a control condition. In addition, relative to control participants, PE participants demonstrated improvements following the sessions in maladaptive pain beliefs, psychological influences on pain beliefs, and pain and aging beliefs, and maintained these gains at follow-up.

\section{Overcoming methodological challenges of previous work}

The current findings are in contrast to previous research that did not find education effective in changing pain knowledge and beliefs (12). This was expected, because we aimed to overcome many of the difficulties encountered by Jones et al (12). First, we derived our content, in part, through focus group discussions with our population of interest. Previous research has generally used a single generalized measure, often developed for the specific research study $(12,14,41)$. Instead, in the present study, knowledge and overall beliefs were captured through two types of measures focusing on general pain beliefs (PBQ and PKBQ) $(14,30,31)$ and acquisition of specific knowledge content (SCKT). Appropriate measurement overcomes difficulties with confusing or misleading items. No clear emphasis on participant interaction was evident throughout the description of the education sessions in Jones et al (12), whereas we specifically harnessed interactivity and learner participation using an empirically supported method of instruction based on constructivist theory (23). This framework, used for both PE and control groups, allowed us to evaluate the impact of the session content (rather than format of delivery) while controlling for expert attention as well as interaction between experts and peers. Jones et al (12) may have encountered motivational challenges, as indicated by the poor attendance rates and staff turnover leading to different staff completing measures at different times. By comparison, in our study, participants could attend during work hours (and receive their salary) rather than attending in their own time, which likely contributed to our excellent attendance rates, the continuity of participants (ie, the same participants completed the measures at all time points) and the overall motivation for participation.

Our design also enabled us to overcome some of the methodological difficulties evident in the work by Long et al (21), although we note that these authors only reported pilot data. First, we used a control group and random assignment that allowed us to attribute changes in the participant scores to the intervention, whereas Long et al (21) and Long (22) used a pre/post design with a very small sample. Furthermore, because Long's (22) educational program was only one component of a multifaceted intervention, it is difficult to determine whether the changes in participant scores were due to the education sessions or to another aspect of the program (ie, consultation clinicians, work groups).

Although our work overcomes many previous methodological challenges, future work using different research designs may provide additional information about the effectiveness, feasibility and reception of PE programs in LTC. Our control condition was designed to hold constant the interactive nature of instruction, hours of instruction and interaction with experts and peers to examine the impact of providing pain information, including pain management strategies, to staff. The value of continuing LTC PE had not been adequately demonstrated in past research. In the future, it would be helpful to examine other aspects of PE such as the mode of delivery. For example, PE could be investigated in different formats such as an interactive format (as was used in the present study), a web-based format and a more traditional didactic presentation limiting dialogue and discussion. This would facilitate the examination of optimal delivery conditions for PE.

The expression of interest in having heard more about clinically useful techniques by control group members (ie, perhaps implying less satisfaction with the group content in the control condition) may be a limitation of our study, because the PE and control groups differed in the manner in which they were received by the participants; this would be important to address in future research.

Interactivity, attendance and session engagement

In the present study, the approach to session development and delivery was novel in that we derived content, in part, through the identification of gaps in knowledge, beliefs and attitudes by our population of 
interest (28). Interactivity within the sessions was accomplished through active dialogue, inevitably shaping sessions around specified needs and concerns as raised by the participants. In addition, participants in the PE sessions were provided with handouts and relevant session content materials (eg, pain assessment measures and scales) to refer to as a means of consolidating knowledge and to help them specifically address the complex clinical issues involved in the pain assessment and management of the dementia patient (42-44). Qualitative analyses supported the appropriateness of the session formats and content. Participants in the PE sessions expressed enthusiasm regarding the applicability of the information to their practice and the manner in which it was delivered.

Research has suggested that the overall nonstimulating and cursory nature of many continuing education programs, coupled with an overwhelming amount of new information, often translates into poor LTC staff participation (45) and may account for null findings in knowledge acquisition. In contrast, in the present study, those who attended the interactive PE sessions engaged themselves in the learning process, as indicated by the consistent improvements in session-specific content knowledge scores retained by the PE participants at posteducation and follow-up. This may be a result of the interactive nature of the program's development and delivery as well as the support of participating facilities to allow staff to attend the sessions as part of their regular paid hours.

\section{Implications}

The results of the present study make several important contributions to the literature regarding continuing PE for front-line LTC staff. To our knowledge, this is the first controlled study to demonstrate the benefits of continuing PE for LTC staff. Although the interactive approach used herein is quite novel in the health care setting, variants are well established in other fields and educational domains (46-48). For example, a social constructivist model of teaching and learning has been used with success in classrooms (46-48). By allowing participants to ask, share and discuss relevant experiences, session instructors were able to engage participants actively in reshaping their belief system in a broad yet personally relevant and meaningful way. This interactive approach was most meaningful for PE participants because it directly related to their daily practices. It was evident through follow-up focus groups that both nurses and SCAs believed it was important to have an understanding of each other's domain of health care knowledge to facilitate better communication of information to other formal and informal caregivers.

Our encouraging findings provide support for the importance of continuing education regarding pain management and assessment within LTC, ultimately challenging outdated and counterproductive beliefs and attitudes retained by LTC staff (ie, nurses and SCAs) throughout their health care careers. These findings have broader

\section{REFERENCES}

1. Hadjistavropoulos T, Herr K, Turk DC, et al. An interdisciplinary expert consensus statement on assessment of pain in older persons. Clin J Pain 2007;23:S1-43.

2. Loeb JL. Pain management in long-term care. Am J Nurs 1999;99:48-52.

3. AGS Panel on Persistent Pain in Older Persons. Clinical practice guidelines: The management of persistent pain in older persons. J Am Geriatr Soc 2002;50:S205-24.

4. Weiner DK, Rudy TE. Attitudinal barriers to effective treatment of persistent pain in nursing home residents. J Am Geriatr Soc 2002;50:2035-40.

5. Hadjistavropoulos T, Craig KD, eds. Pain: Psychological Perspectives. Mahwah: Lawrence Erlbaum Associates, 2004.

6. Kaasalainen S, Coker E, Dolovich L, et al. Pain management decision-making among long-term care physicians and nurses. West J Nurs Res 2007;29:561-80.

7. Horgas AL, Tsai PF. Analgesic drug prescription and use in cognitively impaired nursing home residents. Nurs Res 1998;47:235-42.

8. Horgas AL, Elliott AF. Pain assessment and management in persons with dementia. Nurs Clin North Am 2004;39:593-606.

9. Morrison RS, Sui AL. A comparison of pain and its treatment in advanced dementia and cognitively impaired patients with hip fracture. J Pain Symptom Manage 2000;19:240-8. implications regarding the value of placing continuing education programs in LTC in general. There has been a strong emphasis in the literature on evaluating the utility and validity of continuing education for care staff $(49,50)$. In the present study, we found that interactive continuing education with consistent staff participation is indeed beneficial in facilitating the retention of pain management and assessment of knowledge. This may translate into better pain management practices within the LTC facilities, which may subsequently lead to improved patient-caregiver relationships and lower staff burnout.

When considering the results of the present investigation, several recommendations for future research can be made. First, the amount of time between posteducation and follow-up was relatively short. Examination of PE results over a longer follow-up period would be of interest. In addition, although our focus groups suggested that PE session knowledge translated into practice, additional research on the impact of such knowledge on clinical practice is needed. According to a Cochrane review (23), educational meetings were generally effective in improving professional practice (in addition to knowledge gains), albeit with a small effect. Additional research specifically focusing on LTC PE would be useful in this regard. Finally, as indicated above, direct comparisons of different methods of PE delivery (eg, purely didactic versus interactive versus web-based) would also be important to undertake.

\section{CONCLUSIONS}

We have demonstrated the effectiveness of an educational initiative for LTC staff that focused on pain assessment and management. The program resulted in participants changing past beliefs and attitudes as well as gaining specific content knowledge. Our program and methodology overcame the challenges of previous work in the area, likely accounting for our encouraging findings. The present study makes a unique contribution to the pain management and assessment of continuing education research for LTC staff. The findings of the present study support the applicability and feasibility of an interactive model of learning in LTC nursing and SCA staff.

ACKNOWLEDGMENTS: The authors are grateful to the Regina Qu'Appelle Health Region, the Saskatoon Health Region, and their affiliated long-term care facilities for their participation in this research as well as the staff members whose participation made this work possible.

FUNDING: This research was supported through funding from a Saskatchewan Health Research Foundation team grant. Omeed Ghandehari was supported through funding from the Canadian Institutes of Health Research.

10. Ferrell BR, Novy D, Sullivan MD, et al. Ethical dilemmas in pain management. J Pain 2001;2:171-80.

11. Malloy D, Hadjistavropoulos T. A philosophical value analysis of the Canadian Code of Ethics for Psychologists. Can Psychol 1998;39:187-93.

12. Jones KR, Fink R, Pepper G, et al. Improving nursing home staff knowledge and attitudes about pain. Gerontologist 2004;44:469-78.

13. Martin R, Williams J, Hadjistavropoulos T, Hadjistavropoulos HD, MacLean M. A qualitative investigation of seniors' and caregivers' views on pain assessment and management. Can J Nurs Res 2005;37:142-64.

14. Zwakhalen SM, Hamers JP, Peijnenburg RH, Berger MP. Nursing staff knowledge and beliefs about pain in elderly nursing home residents with dementia. Pain Res Manag 2007;12:177-84.

15. Jones KR, Fink RM, Clark L, Hutt E, Vojir CP, Mellis BK. Nursing home resident barriers to effective pain management: Why nursing home residents may not seek pain medication. J Am Med Dir Assoc 2005;6:10-7.

16. Clark L, Fink R, Pennington K, Jones K. Nurses' reflections on pain management in a nursing home setting. Pain Manag Nurs 2006;7:71-7.

17. Fuchs-Lacelle S, Hadjistavropoulos T, Lix L. Pain assessment as intervention: A study of older adults with severe dementia. Clin J Pain 2008;24:697-707. 
18. Aubin M, Giguere A, Hadjistavropoulos T, Verreault R. The systematic evaluation of instruments designed to assess pain in persons with limited ability to communicate. Pain Res Manag 2007;12:195-203.

19. Hadjistavropoulos T, Marchildon GP, Fine PG, et al. Transforming long-term care pain management in North America: The policyclinical interface. Pain Med 2009;10:506-20.

20. Jones KR, Fink R, Vojir C, et al. Translation research in long-term care: Improving pain management in nursing homes. Worldviews Evid Based Nurs 2004;1:S13-20.

21. Long CO, Morgan BMM, Alonzo TR, Mitchell KM, Bonnell DK, Beardsley M. Improving pain management in long-term care: The "Campaign Against Pain". J Hosp Palliat Nurs 2010;12:1480-55.

22. Long CO. Pain management education in long-term care: It can make a difference. Pain Manag Nurs (In press)

23. Forsetlund L, Bjørndal A, Rashidian A, et al. Continuing education meetings and workshops: Effects on professional practice and health care outcomes. Cochrane Database Syst Rev 2009(2):CD003030.

24. Hean S, Craddock D, O'Halloran C. Learning theories and interprofessional education: A user's guide. Learn Health Soc Care 2009;8:250-262.

25. Beck C, Kosnik C. Innovations in preservice teacher education: A social constructivist approach. Albany: SUNY Press, 2006.

26. Brooks JG, Brooks MG. In search of understanding: The case for constructivist classrooms. Alexandria: Association of Supervision and Curriculum Development, 1993.

27. Thauberger L, Hopkins L, Lacroix K, Campbell B. Labour market study of home care/special care aides in Saskatchewan. 2002.

28. Kaasalainen S, Williams J, Hadjistavropoulos T, et al. Creating bridges between researchers and long-term care homes to promote quality of life for residents. Qual Health Res 2010;20:1689-704.

29. Williams J, Kaasalainen S, Hadjistavropoulos T, et al. A qualitative investigation of injurious falls in long-term care: Perspectives of staff member. Disabil Rehabil 2011;33:423-32.

30. Edwards LC, Pearce SA, Turner-Stokes L, Jones AK. The pain beliefs questionnaire: An investigation of beliefs in the causes and consequences of pain. Pain 1992;51:267-72.

31. Gagliese L, Melzack R. Lack of evidence for age differences in pain beliefs. Pain Res Manag 1997;2:19-28.

32. Green S, Hadjistavropoulos T, Hadjistavropoulos H, Martin R, Sharpe D. A controlled investigation of a cognitive behavioural pain management program for older adults. Behav Cogn Psychother 2009;37:221-6.

33. Walsh DA, Radcliffe JC. Pain beliefs and perceived physical disability of patients with chronic low back pain. Pain 2002;97:23-31.
34. Molton IR, Stoelb BL, Jensen MP, Ehde DM, Raichle KA, Cardenas DD. Psychosocial factors and adjustment to chronic pain in spinal cord injury: Replication and cross-validation. J Rehabil Res Dev 2009;46:31-42.

35. Wallston KA, Wallston BS, DeVellis R. Development of the Multidimensional Health Locus of Control (MHLC) scales. Health Educ Monogr 1978;6:160-70.

36. Maas CJM, Jox JJ. Robustness issues in multilevel regression analysis. Stat Neerl 2004;58:127-37.

37. Bathke AC, Schabenberger O, Tobias RD, Madden LV. Greenhouse-Geisser adjustment and the ANOVA-type statistic: Cousins or twins? Am Stat 2009;63:239-46.

38. Dancey CP, Reidy J. Statistics without maths for psychology: Using SPSS for windows. Upper Saddle River, NJ: Prentice Hall, 2004.

39. Dixon Woods M, Booth A, Sutton AJ. Synthesizing qualitative research: A review of published reports. Qual Res 2007;7:377-422.

40. Fuchs-Lacelle S, Hadjistavropoulos T. Development and preliminary validation of the pain assessment checklist for seniors with limited ability to communicate (PACSLAC). Pain Manag Nurs 2004;5:37-49.

41. Sloman R, Ahern M, Wright A, Brown L. Nurses' knowledge of pain in the elderly. J Pain Symptom Manage 2001;21:317-22.

42. Hadjistavaropoulos T, Hunter P, Dever Fitzgerald T. Pain assessment and management in older adults: Conceptual issues and clinical challenges. Can Psychol 2009;50:241-54.

43. Hadjistavropoulos T, Voyer P, Sharpe D, Verreault R, Aubin M. Assessing pain in dementia patients with comorbid delirium and depression. Pain Manag Nurs 2008;9:48-54.

44. Kaasalainen S, Coker E, Dolovich L, et al. Pain management decision-making among long-term care physicians and nurses. West J Nurs Res 2007;29:561-80.

45. Stolee P, Esbaugh J, Aylward S, et al. Factors associated with the effectiveness of continuing education in long-term care. Gerontologist 2005;45:399-409.

46. Cavalier JC, Klein JD, Cavalier FJ. Effects of cooperative learning on performance, attitude, and group behaviours in a technical team environment. Educ Tech Res 1995;43:61-71.

47. Hand B, Treagust DF, Vance K. Student perceptions of the social constructivist classroom. Sci Educ 1997;81:561-75.

48. Kim JS. The effects of a constructivist teaching approach on student academic achievement, self-concept, and learning strategies. Asia Pac Educ Rev 2005;6:7-19.

49. Fletcher M. Continuing education for healthcare professionals: Time to prove its worth. Prim Care Respir J 2007;16:188-90.

50. Underwood P, Dahlen-Hartfield R, Mogle B. Continuing professional education: Does it make a difference in perceived nursing practice? J Nurses Staff Dev 2004;20:90-8. 


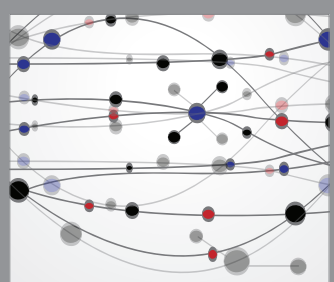

The Scientific World Journal
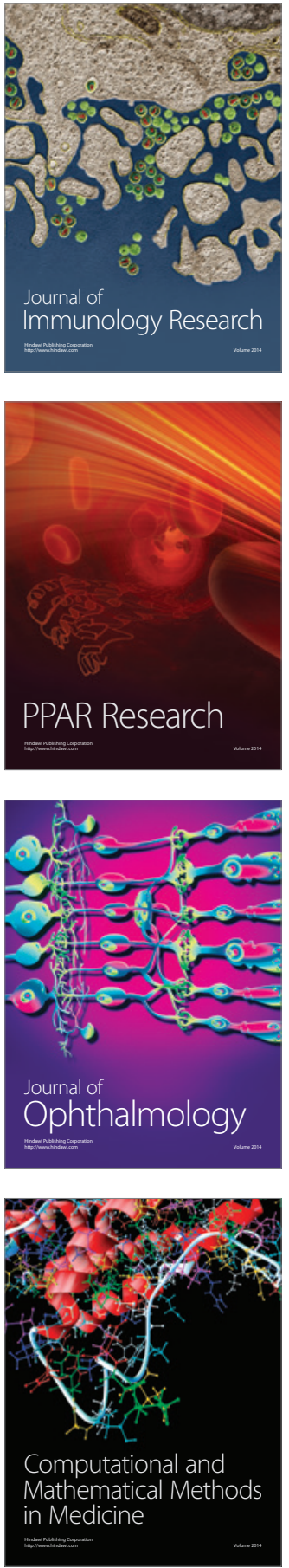

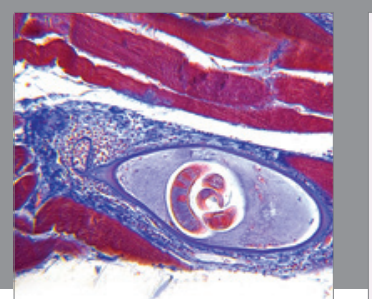

Gastroenterology Research and Practice

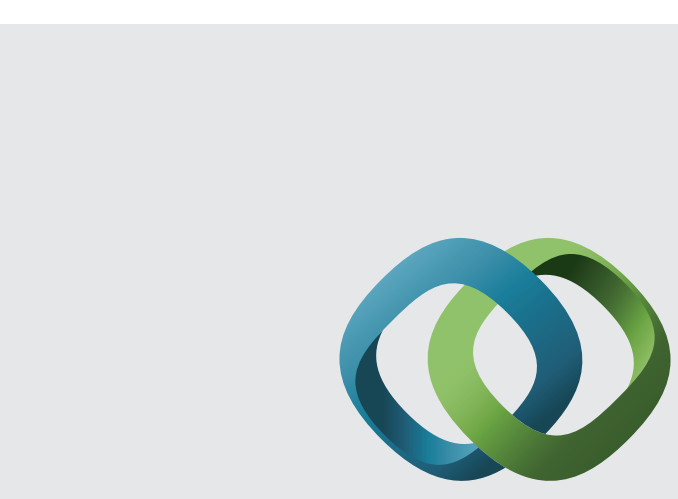

\section{Hindawi}

Submit your manuscripts at

http://www.hindawi.com
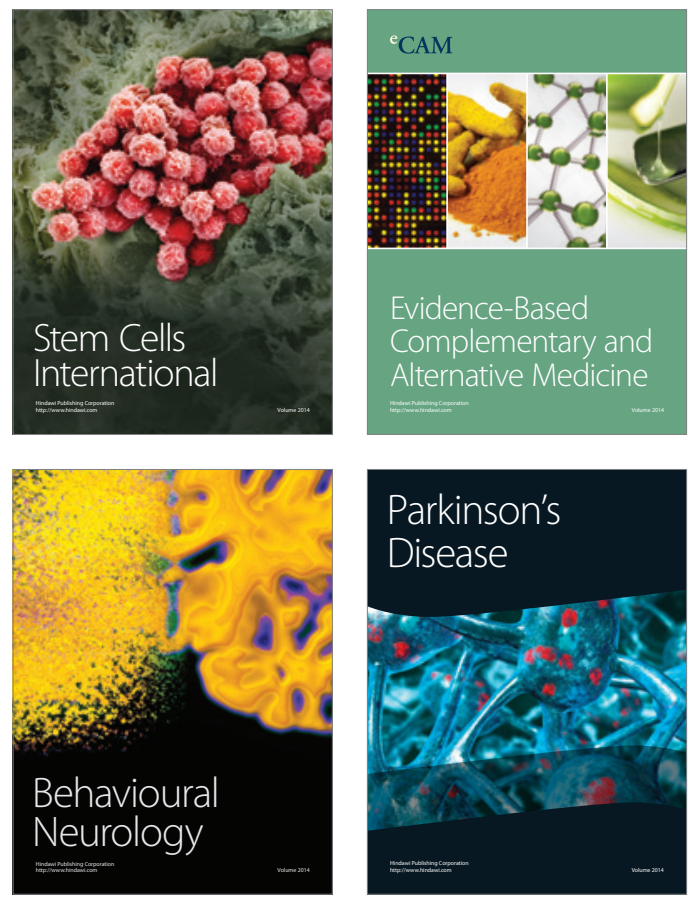
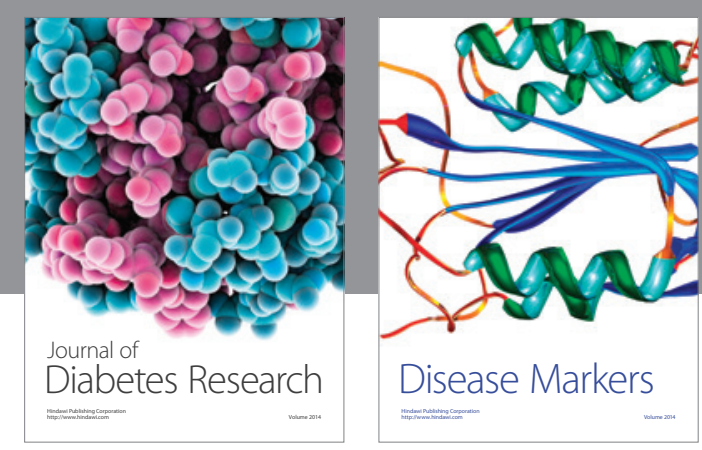

Disease Markers
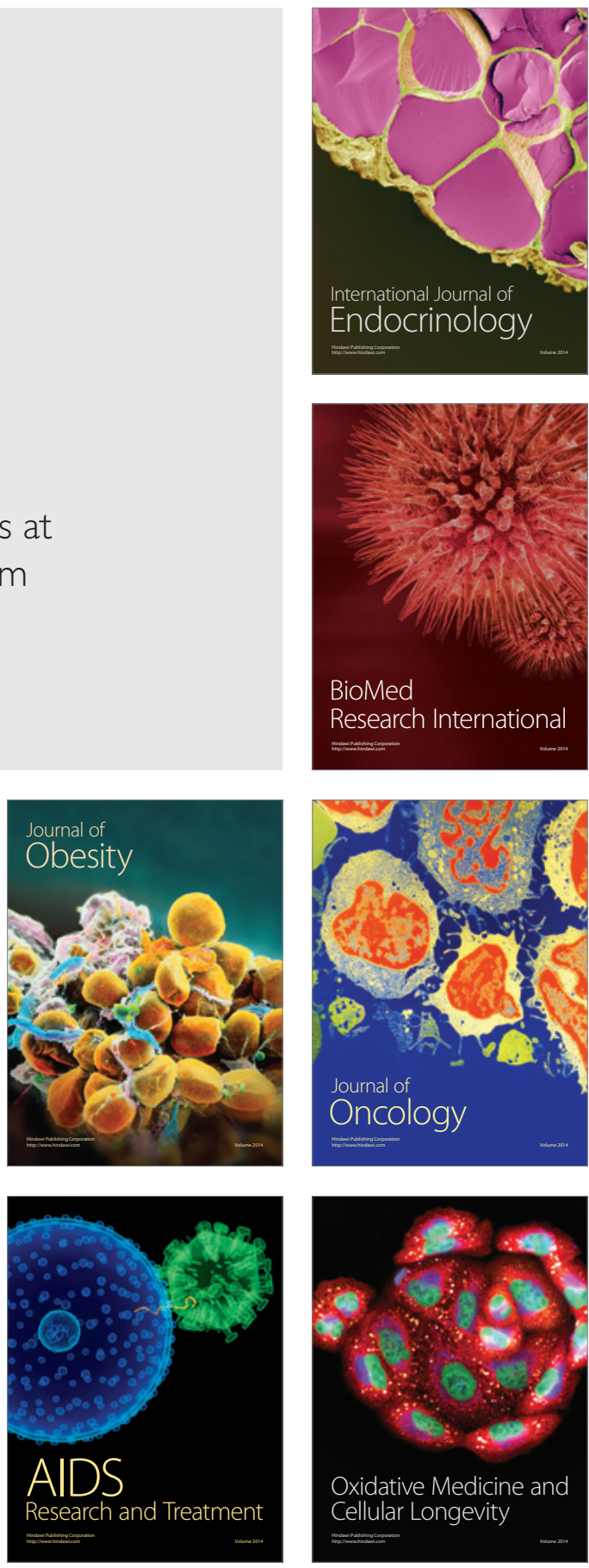